\title{
Produção científica sobre empreendedorismo social e construção de uma agenda para pesquisas futuras: um Estudo Bibliométrico na base Web Of Science (1994-2018)
}

Spuri Garcia, André; de Resende Ribeiro, Olívia Carolina; Meirelles Andrade, Daniela; Nascimento Silva, João Paulo

Produção científica sobre empreendedorismo social e construção de uma agenda para pesquisas futuras: um Estudo Bibliométrico na base Web Of Science (1994-2018)

Administração Pública e Gestão Social, vol. 13, núm. 1, 2021

Universidade Federal de Viçosa, Brasil

Disponible en: http://www.redalyc.org/articulo.oa?id=351564966004

\section{(c) $(1) \Theta$}

Esta obra está bajo una Licencia Creative Commons Atribución-NoComercial-SinDerivar 3.0 Internacional. 


\section{Produção científica sobre empreendedorismo social e construção de uma agenda para pesquisas futuras: um Estudo Bibliométrico na base Web Of Science (1994-2018)}

Scientific production on social entrepreneurship and building a future agenda for research: a Bibliometric Study in the Web of Science (1994-2018)

Producción científica sobre emprendimiento social y construcción de una agenda futura para la investigación: un estudio bibliométrico en la Web of Science (1994-2018)

André Spuri Garcia

Universidade Federal de Lavras, Brasil

andrespurigarcia@gmail.com

Olivia Carolina de Resende Ribeiro

Universidade Positivo, Brasil

oliviacresende@gmail.com

Daniela Meirelles Andrade

Universidade Federal de Lavras, Brasil

daniela.andrade@dae.ufla.br

João Paulo Nascimento Silva

Universidade Federal de Lavras, Brasil

jpnsilvas@gmail.com
Redalyc: http://www.redalyc.org/articulo.oa? $\mathrm{id}=351564966004$

Recepción: 04 Julio 2019

Aprobación: 04 Diciembre 2019

Publicación: 01 Enero 2021

\section{Resumo:}

Objetivo da pesquisa: Este trabalho tem como objetivos analisar como se configura a literatura internacional sobre empreendedorismo social e construir uma agenda de pesquisa para estudos futuros.

Enquadramento teórico: Existem múltiplas definições para o conceito de empreendedorismo social. Em uma perspectiva ampla, o conceito está relacionado com a criação de valor social. Assim, o contraponto com o empreendedorismo privado em relação ao propósito final norteia os estudos sobre empreendedorismo social.

Metodologia: Foi realizada uma análise bibliométrica. Os dados foram coletados a partir da base Web of Science. Para a realização da busca utilizou-se o termo "social entrepreneurship" no título dos artigos. Foram considerados todos os anos da base até 2018. Para análise bibliométrica foi utilizado o software CiteSpace. A agenda de pesquisa foi construída a partir de sugestões de pesquisas propostas em artigos publicados em 2018.

Palavras-ChaVE: Empreendedorismo social, valor social, mudança social, revisão bibliométrica, Empreendedorismo social, valor social, mudança social, revisão bibliométrica.

\section{Resumo:}

Objetivo da pesquisa: Este trabalho tem como objetivos analisar como se configura a literatura internacional sobre empreendedorismo social e construir uma agenda de pesquisa para estudos futuros.

Enquadramento teórico: Existem múltiplas definições para o conceito de empreendedorismo social. Em uma perspectiva ampla, o conceito está relacionado com a criação de valor social. Assim, o contraponto com o empreendedorismo privado em relação ao propósito final norteia os estudos sobre empreendedorismo social.

Metodologia: Foi realizada uma análise bibliométrica. Os dados foram coletados a partir da base Web of Science. Para a realização da busca utilizou-se o termo "social entrepreneurship" no título dos artigos. Foram considerados todos os anos da base até 2018. Para análise bibliométrica foi utilizado o software CiteSpace. A agenda de pesquisa foi construída a partir de sugestões de pesquisas propostas em artigos publicados em 2018. 
Palavras-ChaVe: Empreendedorismo social, valor social, mudança social, revisão bibliométrica, Empreendedorismo social, valor social, mudança social, revisão bibliométrica.

\section{ABSTRACT:}

Research objective: This study aims to analyze how the international literature on social entrepreneurship is configured and to build a research agenda for future studies.

Theoretical framework: There are multiple definitions for the concept of social entrepreneurship. In a broad perspective, the concept is related to the creation of social value. Thus, the counterpoint with private entrepreneurship in relation to the final purpose guides the studies on social entrepreneurship.

Methodology: A bibliometric analysis was performed. The data were collected from the Web of Science database. To perform the search, the term "social entrepreneurship" was used in the title of the articles. All base years were considered until 2018. For bibliometric analysis, the CiteSpace software was used. The research agenda was built from research suggestions proposed in articles published in 2018.

KEYWORDS: Social entrepreneurship, social value, social change, bibliometric review, Social entrepreneurship, social value, social change, bibliometric review.

\section{Resumen:}

Objetivo de la investigación: Este estudio tiene como objetivo analizar cómo se configura la literatura internacional sobre emprendimiento social y construir una agenda de investigación para futuros estudios.

Marco teórico: Existen múltiples definiciones para el concepto de emprendimiento social. En una perspectiva amplia, el concepto se relaciona con la creación de valor social. Así, el contrapunto con el emprendimiento privado en relación al propósito final orienta los estudios sobre emprendimiento social.

Metodología: se realizó un análisis bibliométrico. Los datos se obtuvieron de la base de datos Web of Science. Para realizar la búsqueda se utilizó el término “emprendimiento social” en el título de los artículos. Se consideraron todos los años base hasta 2018. Para el análisis bibliométrico se utilizó el software CiteSpace. La agenda de investigación se construyó a partir de sugerencias de investigación propuestas en artículos publicados en 2018.

Palabras Clave: Emprendimiento social, valor social, cambio social, revisión bibliométrica, Emprendimiento social, valor social, cambio social, revisión bibliométrica.

\section{Abstract:}

Research objective: This study aims to analyze how the international literature on social entrepreneurship is configured and to build a research agenda for future studies.

Theoretical framework: There are multiple definitions for the concept of social entrepreneurship. In a broad perspective, the concept is related to the creation of social value. Thus, the counterpoint with private entrepreneurship in relation to the final purpose guides the studies on social entrepreneurship.

Methodology: A bibliometric analysis was performed. The data were collected from the Web of Science database. To perform the search, the term "social entrepreneurship" was used in the title of the articles. All base years were considered until 2018. For bibliometric analysis, the CiteSpace software was used. The research agenda was built from research suggestions proposed in articles published in 2018.

KEYWORDS: Social entrepreneurship, social value, social change, bibliometric review, Social entrepreneurship, social value, social change, bibliometric review.

\section{Resumen:}

Objetivo de la investigación: Este estudio tiene como objetivo analizar cómo se configura la literatura internacional sobre emprendimiento social y construir una agenda de investigación para futuros estudios.

Marco teórico: Existen múltiples definiciones para el concepto de emprendimiento social. En una perspectiva amplia, el concepto se relaciona con la creación de valor social. Así, el contrapunto con el emprendimiento privado en relación al propósito final orienta los estudios sobre emprendimiento social.

Metodología: se realizó un análisis bibliométrico. Los datos se obtuvieron de la base de datos Web of Science. Para realizar la búsqueda se utilizó el término “emprendimiento social” en el título de los artículos. Se consideraron todos los años base hasta 2018. Para el análisis bibliométrico se utilizó el software CiteSpace. La agenda de investigación se construyó a partir de sugerencias de investigación propuestas en artículos publicados en 2018.

Palabras Clave: Emprendimiento social, valor social, cambio social, revisión bibliométrica, Emprendimiento social, valor social, cambio social, revisión bibliométrica. 


\section{INTRODUÇÃO}

Em um contexto de crise financeira, aumento das desigualdades sociais, problemas demográficos e ambientais de diversas ordens, o empreendedorismo social pode ser visto como um importante instrumento de mudança social (Warnecke, 2018). Alguns autores apontam que ele emerge como uma possível solução para os problemas sociais de ordem econômica (pobreza), social (explosão demográfica e analfabetismo) e ambiental (aquecimento global e degradação ambiental) (Parente, Costa, Santos, \& Chaves, 2011). O discurso neoliberal e a consequente redução do Estado foram fatores determinantes para o seu aumento (Kibler, Salmivaara, Stenholm, \& Terjesen, 2018). Nesse contexto, o debate sobre empreendedorismo social é hoje uma questão importante dentro do campo do empreendedorismo (Zollo, Rialti, Ciappei, \& Boccardi, 2018) e países da Europa, América e Ásia possuem um número significativo de pesquisas teórico-metodológicas sobre o tema (Smachylo, Khalina, \& KylnytSka, 2018; Zahra, Gedajlovic, Neubaum, \& Shulman, 2009; Mair \& Marti, 2006).

Enquanto prática, o empreendedorismo social existe há anos (Collavo, 2018), mas o termo passou a ser utilizado apenas a partir da década de 1990 (Lumpkin, Bacq, \& Pidduck, 2018; Collavo, 2018). Seu conceito ainda está em desenvolvimento (Holland, Hatcher, \& Poole, 2018) e possui múltiplos significados (Collavo, 2018; Schneider, 2017). Essa diversidade conceitual é reforçada pelos diferentes contextos sociais no qual ele ocorre (Collavo, 2018) e a falta de uma definição conceitual prejudica os estudos empíricos. Nesse sentido, Macke, Sarate, Domeneghini e Silva (2018) destacam a importância de uma definição para a consolidação e legitimidade do campo.

Nas últimas décadas ocorreu um crescimento para o empreendedorismo social, tanto em termos teóricos quanto práticos (Choi \& Majumdar, 2014). Em termos práticos, tem sido uma ação estimulada por governos e pela iniciativa privada. Em termos teóricos, o campo do empreendedorismo social consolidou-se nos últimos anos e atualmente conta com eventos e periódicos dedicados à temática, programas de pós-graduação e pesquisadores em diferentes países (Santos, 2012; Dacin, Dacin, \& Tracey, 2011; Mair \& Marti, 2006; Oliveira, 2004). Apesar do crescimento, alguns autores (Holland et al., 2018; Choi \& Majumdar, 2014; Oliveira, 2004) afirmam que o conceito de empreendedorismo social ainda não possui uma definição única. Esse parece ter-se consolidado na prática sem uma precisão conceitual (Holland et al., 2018; Dees, 1998). Para Parente et al. (2011, p. 269), isso causa uma inflação conceitual, isto é, "a falta de uma definição exata é acompanhada por um excesso de significado".

Apesar da não definição do conceito, o empreendedorismo social fica evidente quando comparado ao empreendedorismo privado (Nicolopoulou, 2014; Oliveira, 2004). É possível distinguir algumas características desses dois tipos de empreendimentos. Conforme apresentado por Oliveira (2004), o empreendedorismo social é coletivo e busca soluções para problemas sociais, enquanto o empreendedorismo privado é individual e tem foco no mercado. Dessa forma, compreende-se que enquanto a medida de desempenho do empreendedorismo privado é o lucro por ele gerado, o desempenho do empreendedorismo social é medido pelo impacto social e pelas mudanças sociais que ele produz (Oliveira, 2004). Portanto, apesar de ainda ser um conceito incipiente, o empreendedorismo social é comumente definido a partir da criação de valor social e de seus benefícios e, consequentemente, pode ser entendido como um importante veículo de mudança social (Warnecke, 2018).

Por ser ainda um campo em construção (Holland et al., 2018; Choi \& Majumdar, 2014; Oliveira, 2004), o empreendedorismo social precisa de aportes teórico-metodológicos. Para tanto, faz-se necessário analisar o que já está colocado na literatura. Com o grande volume de eventos, periódicos e publicações que existem hoje em dia, revisões para mapear o estado da arte tornam-se cada vez mais necessárias. Nesse contexto, este trabalho busca responder como se configura a literatura internacional sobre empreendedorismo social. Diante disso, tem como objetivos específicos: 1) analisar como se configura a literatura internacional sobre 
empreendedorismo social, principalmente em relação a autores, países, referências, palavras-chave, entre outros aspectos bibliométricos; e 2) construir uma agenda de pesquisa para estudos futuros. A revisão de literatura aqui proposta atende a chamadas recentes para sistematizar a literatura sobre empreendedorismo social (Macke et al., 2018; Collavo, 2018) e para um aprofundamento teórico do conceito (Lumpkin et al., 2018). Para alcançar esse objetivo será realizada uma revisão bibliométrica, que utiliza técnicas quantitativas para analisar a produção intelectual de um determinado campo científico.

Além desta introdução, o trabalho está dividido em mais cinco tópicos. O segundo tópico traz um referencial teórico sobre empreendedorismo social. No terceiro são apresentados os passos utilizados para a realização da revisão bibliométrica, além de apresentar algumas características e conceitos desse tipo de revisão. O quarto tópico apresenta os resultados e discussões da revisão bibliométrica. O quinto tópico traz uma agenda de pesquisas futuras para o empreendedorismo social. Por fim, o último tópico apresenta as considerações finais, limitações e direcionamentos para novas pesquisas.

\section{FundamentaÇÃo teórica: Definindo Empreendedorismo Social}

Nicolopoulou (2014) destaca que o empreendedorismo social é um campo pré-paradigmático, sem abordagem metodológica e epistemológica dominante. Suas teorias são influenciadas pelas interações que o campo faz com o seu "campo raiz" - empreendedorismo privado (Nicolopoulou, 2014; Oliveira, 2004) - e pelas interações que faz com domínios teóricos relacionados com sustentabilidade, responsabilidade social, inovação, entre outros. Tentar observar o empreendedorismo social como um campo autônomo e paralelo em relação ao empreendedorismo privado tem prejudicado a discussão e sua consolidação teórica (Nicolopoulou, 2014).

O conceito de empreendedorismo social é um conceito contestado, multifacetado e com várias definições concorrentes, o que gera uma fragmentação e dificulta o progresso da teoria - e, consequentemente, dificulta a concretização de perspectivas teórico-metodológicas para pesquisas empíricas (Choi \& Majumdar, 2014). Para Schneider (2017), há várias definições, muitas vezes conflitantes. Dessa forma, não há, no campo do empreendedorismo social, um consenso paradigmático e epistemológico, mas uma luta discursiva entre os vários autores (Nicholls, 2010).

Para Young e Lecy (2014), o consenso sobre o empreendedorismo social existe apenas em um nível alto de abstração, relacionado à necessidade de um propósito social. Entretanto, é difícil classificar e enquadrar o que é o propósito social. Young e Lecy (2014) defendem a ideia de que o conceito não pode ser reduzido a uma única definição, mas sim admitir sua diversidade e complexidade, pois o empreendedorismo social é uma mistura heterogênea de organização privada, governamental e sem fins lucrativos e é preciso reconhecer a riqueza desse campo para desenvolver sua agenda de pesquisa. Essa seria uma vantagem do conceito de empreendedorismo social: abandonar a ideia de que benefícios sociais só podem ser gerados por organizações sem fins lucrativos e, mais que isso, que empreendimentos sociais não podem obter sucesso financeiro. A partir disso, Young e Lecy (2014) ressaltam que o empreendedorismo social pode incorporar vários tipos de organizações, como empresas privadas, empresas sociais, cooperativas, organizações sem fins lucrativos, parcerias público-privadas e organizações híbridas.

Nesse contexto de múltiplas definições, Austin, Stevenson e Wei-Skillern (2012) as dividem em estreitas e amplas. As definições estreitas apresentam o empreendedorismo social como atividade realizada por organizações do terceiro setor. Em uma perspectiva ampla inclui, além dessas organizações, as ações de responsabilidade social das empresas, a filantropia individual e as instituições de caridade. Fischer e Comini (2012) destacam três correntes de pensamento sobre o empreendedorismo social: perspectiva europeia, americana e a linha que prevalece nos países em desenvolvimento. A corrente europeia enfatiza as ações das organizações da sociedade civil. A corrente americana diz respeito às empresas do setor privado agindo para resolver problemas sociais. Por fim, a terceira corrente "enfatiza iniciativas de mercado que visam reduzir a 
pobreza e transformar as condições sociais das pessoas marginalizadas e excluídas” (Fischer \& Comini, 2012, p. 367).

Smachylo et al. (2018, p. 242), por meio de uma revisão de literatura, definem o empreendedorismo social como uma "forma única, inovadora, híbrida de negócios, que é projetada principalmente para resolver problemas sociais agudos”. Rivera, Santos, Martín-Fernández, Requero e Cancela (2018, p. 2) entendem o empreendedorismo social como "um processo inovador de criação, implementação e sustentabilidade de projetos cujo objetivo principal não é a maximização do lucro pessoal, mas a melhoria da sociedade". O empreendedorismo social contribui com o bem-estar da população, gera empregos e pode, também, gerar crescimento econômico (Rivera et al., 2018).

Nesse mesmo sentido, Kummitha (2018, p. 93) entende o empreendedorismo social como "um processo inovador de criação de valor social, que aborda as necessidades e preocupações das seções excluídas". Servantie e Rispal (2018, p. 311) expõem que no empreendedorismo social "o valor social e o desenvolvimento são priorizados sobre os resultados econômicos", no entanto, a discussão se torna complexa pois os valores sociais são considerados multifacetados, uma vez que envolvem questões relacionadas ao meio-ambiente, saúde, saneamento básico, questóes econômicas e questões sociais de diversas ordens (Kummitha, 2018; Servantie $\&$ Rispal, 2018). Assim, o empreendedorismo social acontece em diferentes setores como, por exemplo, arte, cultura, agricultura, setor bancário, entre outros e pode se manifestar de diversas formas (Collavo, 2018).

O empreendedorismo social envolve a descoberta, definição e exploração de oportunidades para criar riqueza social (Soompon, 2018) - o conceito de oportunidades aparece mais fortemente no campo do empreendedorismo privado e pode ser entendido como falhas de mercado ou mudanças exógenas que possibilitam criação de novos empreendimentos (Alvarez \& Barney, 2007). Também pode ser entendido como um novo tipo de modelo de negócio, que busca oferecer produtos ou serviços para atender às demandas básicas de classes menos favorecidas que permanecem insatisfeitas pelos atuais sistemas de mercado.

Para Warnecke (2018), o empreendedorismo social se situa em um ambiente político e institucional complexo e rígido, o que pode dificultar o surgimento desses empreendimentos. Kokko (2018) destaca que os empreendimentos sociais devem criar uma rede com stakeholders (empresas privadas, organizações públicas, organizações do terceiro setor) inseridos em lógicas distintas. Em consequência, há uma necessidade de balancear múltiplas lógicas e suas racionalidades associadas. Segundo Warnecke (2018, p. 375), "o ecossistema do empreendedorismo social inclui fundações, centros de pesquisa de empresas sociais, incubadoras, centros de treinamento, escolas e financiadores, entre outras instituições".

Chandra (2017) aponta que o empreendedorismo social é uma forma de emancipação, relação ainda não estudada com profundidade pela literatura. Assim, pode ser uma forma de libertar o indivíduo de restrições ideológicas e de comportamentos estabelecidos no passado. Para Chandra (2017), o formato de organização não focado exclusivamente no lucro permite a emancipação dos envolvidos com o empreendimento.

Em síntese, esse breve referencial teórico mostra uma discussão recente sobre o conceito de empreendedorismo social. Apesar de um conceito ainda não definido, o contraponto com o empreendedorismo privado, principalmente em relação ao propósito final, norteia os estudos sobre empreendedorismo social. A partir disso, as discussões giram em torno dos atores e organizações responsáveis por esse tipo de empreendedorismo.

\section{Metodologia}

A presente pesquisa se caracteriza como uma análise bibliométrica. Este tipo de análise emprega técnicas quantitativas para avaliar a produção acadêmica de um determinado campo em relação a autorias, coautorias, citações, cocitações, periódicos, palavras-chave, volume de publicações e distribuição da bibliografia (Prado et al., 2016). Essa técnica de análise demonstra a configuração, o desenvolvimento e a trajetória de um determinado campo (Liu et al., 2014). 
Como qualquer metodologia, a análise bibliométrica precisa ser clara em relação aos métodos utilizados. Diante disso, foi utilizada neste trabalho uma adaptação do framework de pesquisa utilizado por Prado $e t$ al. (2016). Esse framework descreve algumas etapas a serem seguidas pelo pesquisador e estão relacionadas com a busca de dados, seleção, organização e análise do material que constituirá o corpus do estudo.

Na primeira etapa da construção da pesquisa bibliométrica é importante definir os termos de busca e a base na qual será realizada. Para analisar a literatura sobre empreendedorismo social foi utilizada a base de dados da Web of Science (coleção principal) da Thomson Reuters Scientific. A escolha por uma única base de dados se deve à padronização das informações levantadas. Quanto à base escolhida, destaca-se sua relevância, abrangência e confiabilidade. Além disso, essa base possibilita que se façam exportações das buscas e referências para a utilização do software de análise bibliométrica CiteSpace (Chen, 2006), que será utilizado neste trabalho. Esse software proporciona a construção do que Chen (2006) chama de Research front (os trabalhos mais citados de um campo científico e sua configuração), bem como da Intellectual base (as citações e cocitações na literatura científica). Ambos os conceitos são importantes para verificar tendências e padrões na literatura de um determinado campo de conhecimento (Chen, 2006).

Para a realização da busca utlizou-se o termo "social entrepreneurship" - entre aspas, com o intuito de aparecer o termo inteiro. O termo buscado deveria constar no título dos artigos. Foram considerados todos os anos da base até 2018 - último ano completo - e todos os idiomas e categorias. Um filtro utilizado foi o tipo de trabalho, que deveria ser artigo científico, o que exclui demais formas de trabalho. Essa busca resultou em 358 artigos. Adiante, para utilização do CiteSpace foi necessário realizar o download das referências dos artigos, que foram exportadas em formato de planilha eletrônica e também em formato de texto para o software (Chen, 2006).

A análise da Research front consiste em analisar os 358 trabalhos encontrados na busca. Essa análise inclui a frequência de publicações por ano, para verificar o início e se existem picos e (ou) quedas de publicações, a frequência de publicação por países, a co-autoria entre países e os países com maior centralidade. Importante destacar que a co-autoria consiste na parceria entre autores de diferentes nacionalidades, enquanto a centralidade diz respeito ao número de parcerias que um país faz com o outro. Realizou-se também a frequência de publicações por periódico e seus respectivos fatores de impacto (esses fatores são coletados na própria Web Of Science).

Ainda na análise da Research front, realizou-se a análise de co-ocorrência e explosão (citation burst) de palavras-chave. A co-ocorrência é baseada na Author Keywords, ou seja, quando o artigo utiliza a palavrachave, e na Keyword Plus, que é quando uma determinada palavra aparece com frequência no título das obras referenciadas pelo artigo. Por sua vez, a explosão de palavras-chave consiste em palavras que passaram a ter grande número de co-ocorrências em um período específico. Realizou-se, ainda, a análise de categorias para verificar em qual categoria cada artigo estava indexado (essas categorias estão na Web Of Science).

A mais importante análise da Reserach Front consiste na análise do número de citações dos artigos selecionados, pois é por meio desse resultado que se pode definir os trabalhos que representam as principais temáticas tratadas pelo campo. Para operacionalizar essa etapa foram analisadas informações relacionadas ao número de citações, levantadas na Web of Science. Os artigos mais citados foram lidos na íntegra e um breve resumo de cada um deles foi apresentado nos resultados.

Por sua vez, a análise da Intellectual base de uma frente de pesquisa mostra as citações e co-citações na literatura científica, de autores e de documentos (Chen, 2006). A avaliação da co-citação de autores está relacionada com os autores referenciados pelos artigos da busca. Uma co-citação ocorre quando um artigo da busca faz referência a dois autores ao mesmo tempo. Em sentido análogo, a co-citação de trabalhos aponta os documentos que foram citados por dois ou mais trabalhos da busca. A principal contribuição dessa etapa é a análise das referências utilizadas pela amostra encontrada. A operacionalização dessa etapa é realizada por meio da inserção dos dados coletados na Web of Science no CiteSpace. 
Após a análise bibliométrica apresentou-se uma agenda de pesquisas futuras. Essa agenda foi construída mediante leitura de alguns artigos do ano de 2018 e considerando a agenda de pesquisas futuras apontada nesses artigos. Ressalta-se que a construção da agenda não levou em consideração todos os artigos do ano 2018, pois alguns não apresentavam sugestões de pesquisas futuras, conforme verificado a partir de uma leitura inicial. Além disso, alguns artigos não foram encontrados na íntegra. Quanto ao ano, foi escolhido apenas o ano mais recente, pois a escolha de outros anos resultaria em um grande volume de artigos. Dessa forma, a agenda de pesquisas futuras considerou 23 publicados em 2018.

\section{Resultados e Discussões}

Para melhor compreensão, os resultados foram divididos em tópicos. O primeiro apresenta a análise da Research Front. O segundo apresenta a análise da Intellectual base.

\subsection{Research Front}

Inicialmente apresentamos a frequência de publicações por ano (Gráfico 1). Por meio do gráfico é possível observar que estudos sobre empreendedorismo social são recentes. Apesar do primeiro trabalho da busca ter sido publicado em 1994, até 2005 o número de publicações era baixo.

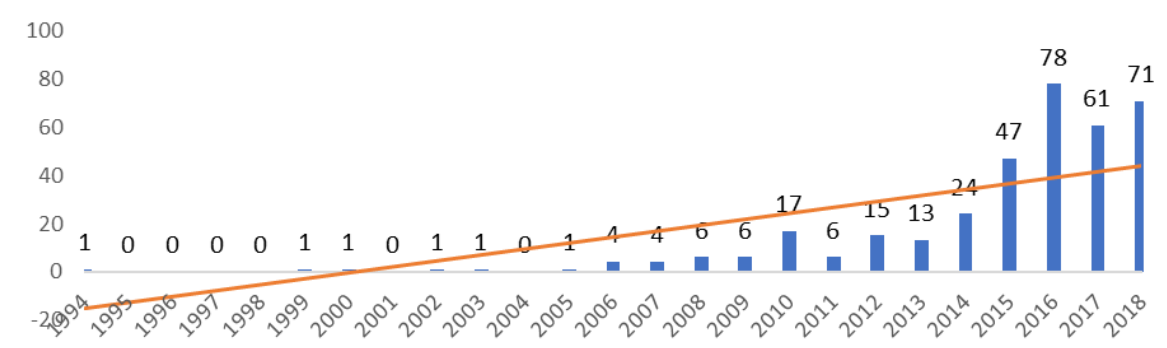

Gráfico 1 - Número de publicações por anos

Fonte: elaborado pelos autores a partir da Web Of Science.

A partir de 2006 o número de publicações aumenta consideravelmente, atingindo o ápice em 2016 (78 trabalhos publicados). A explosão do campo a partir de 2006 pode ser explicada pela publicação dos trabalhos de Mair e Marti (2006), Peredo e McLean (2006) e Weerawardena e Mort (2006), seminais para o campo do empreendedorismo social, o que pode ser verificado a partir do grande número de citações desses trabalhos. O gráfico está de acordo com o exposto por Collavo (2018) e Oliveira (2004), que ressaltam que o empreendedorismo social existe há anos, mas o termo passou a ser amplamente utilizado apenas recentemente. Segundo Oliveira (2004), o termo emerge na década de 1990 diante dos cortes de gastos observados no setor público e das diversas problemáticas existentes.

Em relação aos países, a Tabela 1 apresenta a frequência de publicação por país, o ano da primeira publicação e a centralidade. Os maiores destaques são Estados Unidos, Inglaterra, Espanha, Austrália e Canadá. Dos 15 países listados, 7 iniciaram a publicação em empreendedorismo social a partir de 2010. A partir disso, é possível inferir que o campo tende a crescer nos próximos anos, pois mais países estão pesquisando sobre o assunto. Isso pode reforçar e legitimar o tema, trazendo contribuições teóricometodológicas de diferentes contextos. 
Tabela 1 - Frequência de publicação por país

\begin{tabular}{lllll}
\hline País & Freq. \% & Início & Centralidade \\
\hline Estados & & & & \\
Unidos & 110 & 30,7 & 1994 & 0.20 \\
\hline Inglaterra & 32 & 8,9 & 2004 & 0.25 \\
\hline Espanha & 28 & 7,8 & 2006 & 0.27 \\
\hline Austrália & 21 & 5,8 & 2002 & 0.01 \\
\hline Canadá & 21 & 5,8 & 2006 & 0.00 \\
\hline França & 16 & 4,4 & 2012 & 0.46 \\
\hline Itália & 16 & 4,4 & 2008 & 0.02 \\
\hline Alemanha & 13 & 3,6 & 2014 & 0.00 \\
\hline India & 13 & 3,6 & 2007 & 0.03 \\
\hline Holanda & 13 & 3,6 & 1999 & 0.00 \\
\hline China & 13 & 3,6 & 2014 & 0.15 \\
\hline Rússia & 12 & 3,3 & 2015 & 0.00 \\
\hline Parcial & 308 & $86,6 \%$ & & \\
\hline $\begin{array}{l}\text { Outros } \\
\text { países }\end{array}$ & 48 & $13,4 \%$ & &
\end{tabular}

Fonte: Elaborado pelos autores.

Outra inferência importante a partir da Tabela 1 é a pouca ou nenhuma presença de países africanos e latino-americanos. As pesquisas estão concentradas basicamente em países desenvolvidos. A partir da teoria dos vazios institucionais e considerando que o empreendedorismo social tem por objetivo resolver problemas sociais, países subdesenvolvidos deveriam buscar entender os empreendimentos sociais e sua importância nesses contextos. Além disso, Zahra et al. (2009, p. 520) ressaltam que os empreendedores sociais "desempenharam um papel vital na melhoria das condiçóes sociais adversas, especialmente nas economias subdesenvolvidas e emergentes".

Adiante, a Figura 1 mostra a co-autoria entre os países. A centralidade indica o número de publicações com outros países. Quanto maior a centralidade, maior o número de publicações com outros países. Os países mais centrais são Estado Unidos, Espanha, França e Inglaterra. 


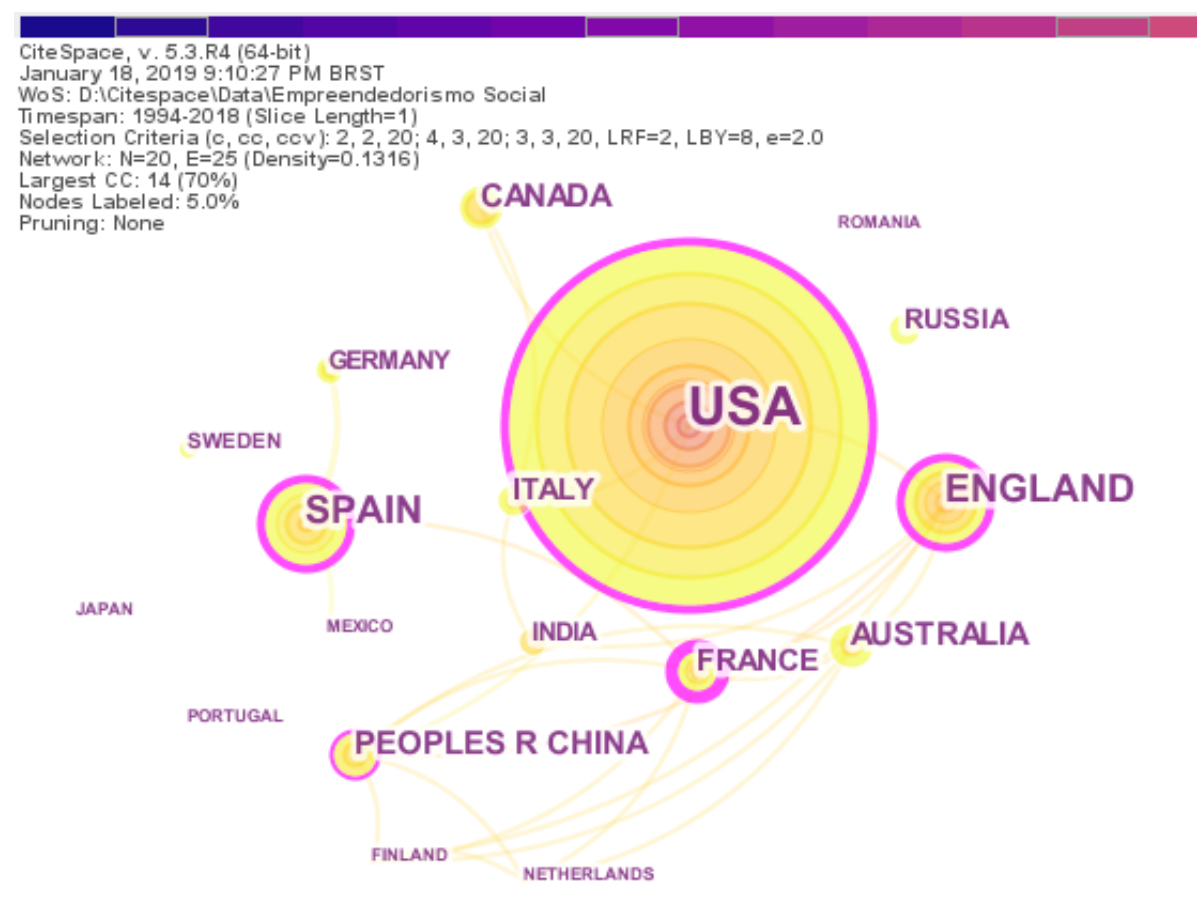

FIGURA 1

Rede de coautoria entre países

Fonte: Elaborado pelos autores.

A relação com outros países é importante para ampliar o contexto das pesquisas. Especificamente no campo do empreendedorismo social, a relação com outros países permite a construção de trabalhos que levem em consideração lógicas institucionais distintas, uma vez que cada país possui suas próprias instituições formais e informais.

Em relação às palavras-chave, essa é uma dimensão importante da análise bibliométrica e tem como objetivo mostrar as principais abordagens ou temáticas de um determinado campo, ou seja, mostra o conteúdo central dos artigos e, consequentemente, os tópicos de pesquisa. A Figura 2 apresenta a co-ocorrência de palavras-chave, que é baseada na Author Keywords e na Keyword Plus. Quando uma determinada palavra ou expressão aparece tanto na Author Keyword, quanto na Keyword Plus, existe uma coocorrência. $\mathrm{O}$ tamanho do nó está relacionado com a frequência de co-ocorrência. 


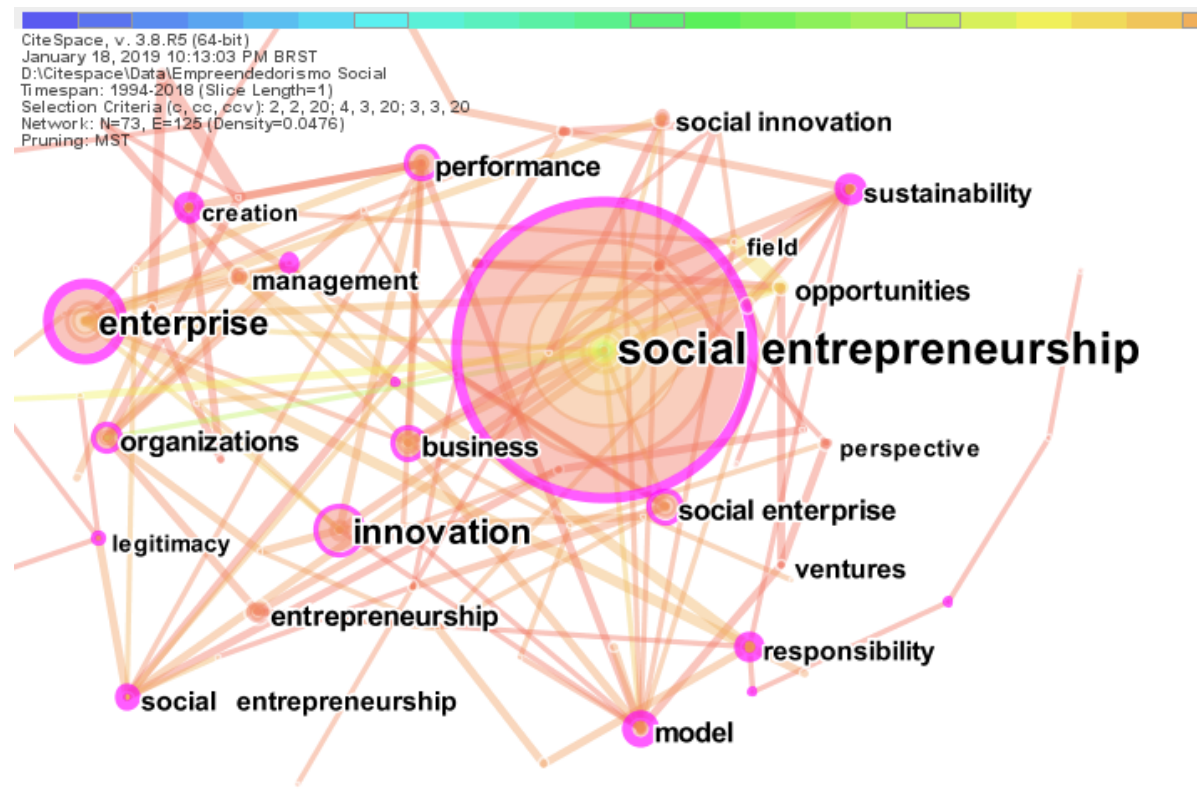

FIGURA 2

Coocorrências de palavraschave

Fonte: Elaborado pelos autores.

A palavra-chave com maior número de co-ocorrência é social entrepreneurship(217 co-corrências). Ressalta-se que a expressão aparece duas vezes na Figura 2. O arquivo utilizado no CiteSpace é um arquivo de texto gerado pela Web Of Science e nesse arquivo a expressão social entrepreneurship apareceu de duas formas diferentes, sendo uma delas com dois espaços entre os termos social. entrepreneurship, o que fez com que o CiteSpace reconhecesse como dois termos distintos. Adiante, é importante notar que muitas palavras inicialmente relacionadas ao empreendedorismo privado também aparecem como, por exemplo, enterprise (63), innovation (45), organization (32), opportunity (32), business (30), performance (23), management (21). Dessa forma, nota-se uma forte ligação entre o campo do empreendedorismo social e seu campo de origem. $\mathrm{O}$ empreendedorismo social ainda é conceituado a partir de suas diferenças em relação ao empreendedorismo privado, mas alguns conceitos são comuns aos dois campos.

Adiante, a Tabela 3 apresenta, cronologicamente, as 13 palavras-chave que tiveram citation burst, ou seja, uma explosão de citações. A primeira coluna exibe as palavras-chave, a segunda mostra a força de ruptura, a terceira e quarta coluna apontam, respectivamente, o período inicial e final da explosão de citação. Finalmente, a quinta coluna ilustra, em vermelho, o intervalo de tempo da explosão. 
Tabela 3 - Explosão de palavras-chave (citation burst)

\begin{tabular}{|c|c|c|c|c|}
\hline \multirow{2}{*}{ Palavra-chave } & \multicolumn{4}{|c|}{ Explosão de citação } \\
\hline & Força & Início & Fim & $1945-2018$ \\
\hline \multicolumn{5}{|l|}{ social } \\
\hline entreprer & 67.104 & 2008 & 2011 & 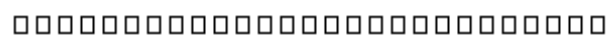 \\
\hline discovery & 22.763 & 2010 & 2014 & 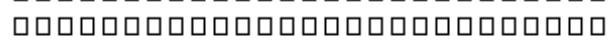 \\
\hline organization & 30.421 & 2010 & 2012 & 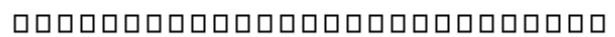 \\
\hline opportunity & 22.621 & 2010 & 2014 & 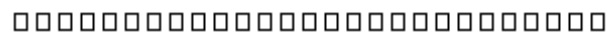 \\
\hline value creation & 27.608 & 2012 & 2014 & 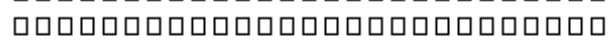 \\
\hline strategy & 18.186 & 2012 & 2016 & 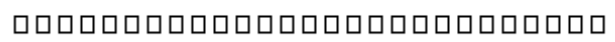 \\
\hline field & 23.839 & 2013 & 2015 & 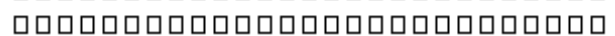 \\
\hline responsibility & 2.524 & 2014 & 2015 & 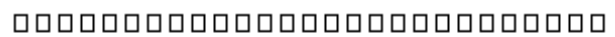 \\
\hline india & 25.158 & 2015 & 2016 & 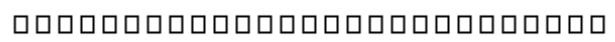 \\
\hline ethics & 21.539 & 2015 & 2016 & घ \\
\hline identity & 17.929 & 2015 & 2016 & 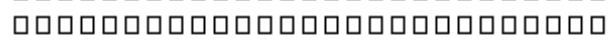 \\
\hline institutional void & 14.326 & 2015 & 2016 & घ \\
\hline policy & 14.425 & 2016 & 2018 & 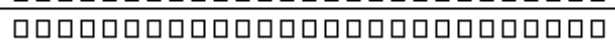 \\
\hline
\end{tabular}

Fonte: Elaborado pelos autores a partir do algoritmo de CiteSpace.

Observando a Tabela 3 é possível fazer algumas inferências sobre a evolução do campo do empreendedorismo social. A palavra que define o campo, social entrepreneurship, explode em termos de citação apenas em 2008, o que comprova o quão recente é o campo. A explosão das palavras discovery e opportunity em 2010 demonstra que o campo do empreendedorismo social buscou referências no empreendedorismo privado, pois essas são categorias importantes no campo raiz e ganharam força a partir do trabalho seminal de Shane e Venkataraman (2000). A ideia de descoberta de oportunidades foi incorporada ao empreendedorismo social. Mair e Marti (2006) e Sooampon (2018), por exemplo, afirmam que o empreendedorismo social também ocorre a partir da descoberta e exploração de oportunidades. Mair e Noboa (2006) utilizam, inclusive, o conceito de oportunidades sociais para se referirem a oportunidades que podem ser exploradas para criação de empreendimentos sociais. Nesse sentido, Mair e Marti (2006) afirmam que o empreendedorismo social reproduziu a evolução teórica do empreendedorismo.

Em 2012 a expressão value creation teve explosão de citação. Atualmente, várias definições enfatizam a criação de valor social como um contraponto ao empreendedorismo privado, que tem como foco a criação de valor econômico (Mair \& Marti, 2006). Mais recentemente, ocorre a explosão de citação do termo "vazio institucional" (institutional void) (Tabela 3). O institutional void mostra a relação entre instituições e o empreendedorismo social e busca entender como as instituições formais (organizações, normas, regulamentos) e informais (valores, culturas) influenciam, estimulam ou restringem o empreendedorismo social. Stephan, Uhlaner e Stride (2015) e Saebi, Foss e Linder (2019) afirmam que a motivação para o empreendedorismo social aumenta em ambientes com recursos escassos e onde as instituições governamentais são menos ativas, ou seja, onde há vazios institucionais.

Adiante, em relação as categorias o banco de dados da coleção principal da Web Of Science anexa cada artigo em uma ou mais categorias de assunto, de acordo com o periódico no qual foi publicado. A rede (Figura 3) mostra as categorias com maior contagem de co-ocorrências. O tamanho do nó está relacionado com a quantidade de artigos em cada categoria. 


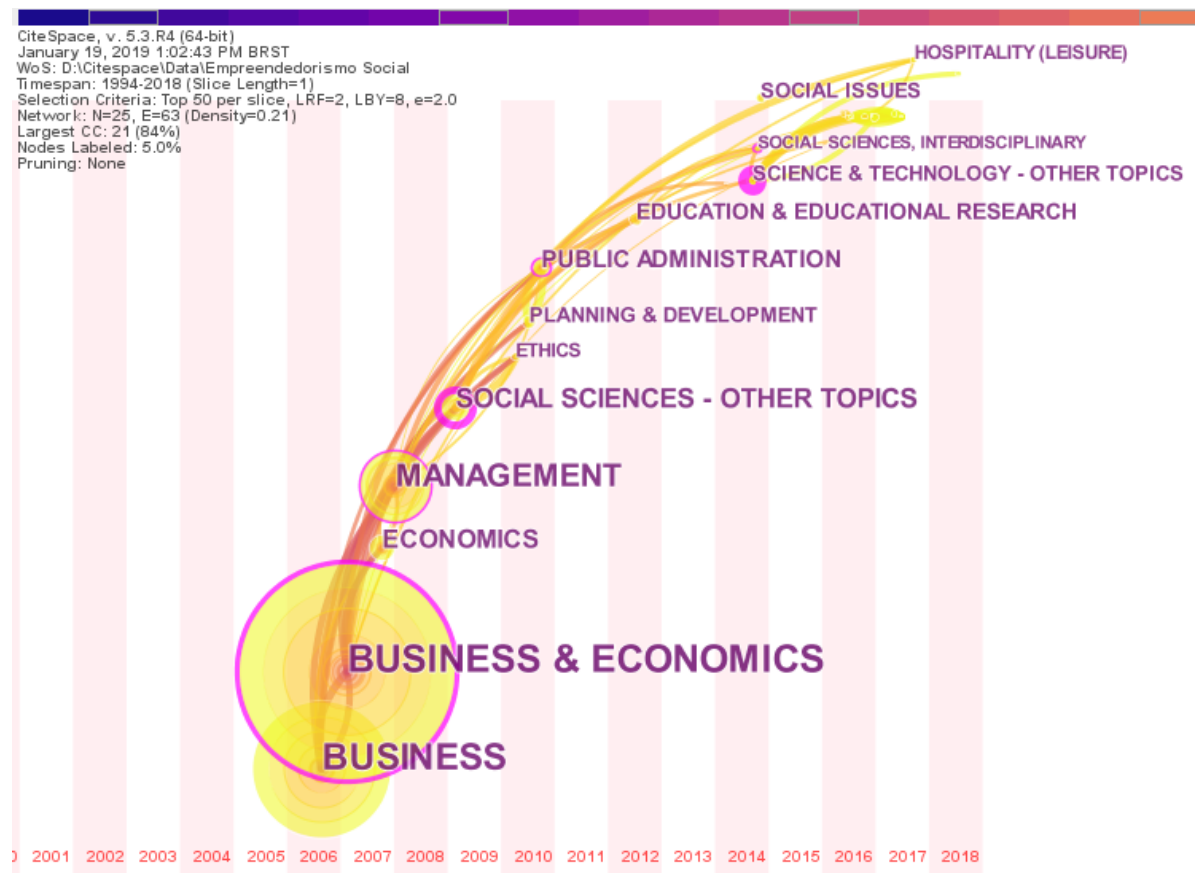

FIGURA 3

Coocorrência de categorias

Fonte: Elaborado pelos autores.

Importante destacar a pouca quantidade de artigos indexados na categoria Administração Pública. Conforme já apontado, pela perspectiva do vazio institucional (Stephan, 2015; Saebi et al., 2019) o empreendedorismo social tende a ocorrer com maior frequência em locais onde instituições governamentais são pouco atuantes. Nesse sentido, um diálogo com o campo da Administração Pública pode ser benéfico para o campo, pois pode oferecer teorias relacionadas ao funcionamento das instituições governamentais, além de possibilitar estudos empíricos relacionados à teoria dos vazios institucionais.

Além disso, as organizações da administração pública, assim como os empreendimentos sociais, trabalham com lógicas institucionais múltiplas e objetivos sociais. Consequentemente, o empreendedorismo social pode buscar teorias e metodologias no campo da Administração Pública. Além disso, Mair e Marti (2006) colocam que o diálogo mais profundo com outros campos é essencial para o desenvolvimento do conceito.

Em relação aos periódicos, a Tabela 4 apresenta aqueles que mais publicaram trabalhos da busca. A análise de periódicos mostra se determinado journal é referência em determinada temática, o que indicaria um caminho para buscas de referências. Nota-se (Tabela 4) que não existe uma grande discrepância de um determinado periódico, mas no conjunto os journals da tabela abaixo formam um conjunto interessante de fonte de dados para os pesquisadores que buscam estudar empreendedorismo social. 
Tabela 4 - Periódicos que mais publicaram os artigos da frente de pesquisa

\begin{tabular}{llll}
\hline Periódico & Freq. & \% & $\begin{array}{l}\text { Fator de } \\
\text { impacto }\end{array}$ \\
\hline Journal of Business Ethics & 14 & 3,93 & 2,917 \\
\hline Entrepreneurship and Regional Development & 13 & 3,65 & 2,791 \\
\hline Journal of Social Entrepreneurship & 12 & 3,37 & - \\
\hline Voluntas & 10 & 2,80 & 1,273 \\
\hline Journal Of Business Research & 7 & 1,96 & 2,509 \\
\hline Social Enterprise Journal & 7 & 1,96 & - \\
\hline Academy of Management Learning Education & 5 & 1,40 & 2,866 \\
\hline International Journal Of Contemporary & & & \\
Hospitality Management & 5 & 1,40 & 2,874 \\
\hline Journal Of Cleaner Production & 5 & 1,40 & 5,651 \\
\hline Journal Of Small Business Management & 5 & 1,40 & 3,284 \\
\hline Parcial & 83 & 23,31 & \\
\hline Demais periódicos & 273 & 76,69 & \\
\hline Total Geral & 356 & 100 & \\
\hline
\end{tabular}

Fonte: Elaborado pelos autores a partir da Web Of Science.

Importante destacar que os seis artigos mais citados da busca (Tabela 5) não estão publicados em nenhum dos journals listados na Tabela 4, contudo, ela aponta dois periódicos específicos para o empreendedorismo social, a saber, Journal of Social Entrepreneurship e Social Enterprise Journal, além de outros periódicos com perspectivas marginais como, por exemplo, Voluntas, Journal of Business Ethics e Journal Of Cleaner Production.

Adiante, um dos resultados bibliométricos mais relevantes é a identificação dos artigos mais citados. Esses artigos podem demonstrar os temas mais relevantes dentro de um campo, isto é, possíveis tendências, além de definições importantes. Neste sentido, a Tabela 5 apresenta os dez artigos mais citados, os quais foram publicados a partir de 2005, o que reforça a ideia de um campo recente e em construção. Esses artigos são discutidos na sequência. 
Tabela 5 - Artigos mais citados da frente de pesquisa

\begin{tabular}{|c|c|c|c|c|}
\hline$\#$ & Título & Autores & Periódico & Cit. \\
\hline 1 & $\begin{array}{l}\text { Social entrepreneurship research: } A \\
\text { source of explanation, prediction, } \\
\text { and delight }\end{array}$ & Mair,e Marti (2006) & $\begin{array}{l}\text { Journal of } \\
\text { World Business }\end{array}$ & 912 \\
\hline 2 & $\begin{array}{l}\text { Social entrepreneurship: } \text { A critical } \\
\text { review of the concept }\end{array}$ & $\begin{array}{l}\text { Peredo e McLean } \\
(2006)\end{array}$ & $\begin{array}{l}\text { Journal of } \\
\text { World Business }\end{array}$ & 482 \\
\hline 3 & $\begin{array}{l}\text { Social Entrepreneurship: Why We } \\
\text { Don't Need a New Theory and How } \\
\text { We Move Forward From Here }\end{array}$ & $\begin{array}{l}\text { Dacin, Dacin e } \\
\text { Matear (2010) }\end{array}$ & $\begin{array}{l}\text { Academy of } \\
\text { Management } \\
\text { Perspectives }\end{array}$ & 370 \\
\hline 4 & $\begin{array}{l}\text { Research in Social Entrepreneurship: } \\
\text { Past Contributions and Future } \\
\text { Opportunities }\end{array}$ & $\begin{array}{l}\text { Short, Mosse } \\
\text { Lumpkin (2009) }\end{array}$ & $\begin{array}{l}\text { Strategic } \\
\text { Entrepreneurship } \\
\text { Journal }\end{array}$ & 369 \\
\hline 5 & $\begin{array}{l}\text { Investigating social } \\
\text { entrepreneurship: } A \\
\text { multidimensional model }\end{array}$ & $\begin{array}{l}\text { Weerawardena e } \\
\text { Mort (2006) }\end{array}$ & $\begin{array}{l}\text { Journal of world } \\
\text { Business }\end{array}$ & 363 \\
\hline 6 & $\begin{array}{l}\text { Social Entrepreneurship: A Critique } \\
\text { and Future Directions }\end{array}$ & Dacin et al. (2011) & $\begin{array}{l}\text { Organization } \\
\text { Science }\end{array}$ & 260 \\
\hline 7 & $\begin{array}{l}\text { A Positive Theory of Social } \\
\text { Entrepreneurship }\end{array}$ & Santos (2012) & $\begin{array}{l}\text { Journal of } \\
\text { Business Ethics }\end{array}$ & 221 \\
\hline 8 & $\begin{array}{l}\text { Venturing for others with heart and } \\
\text { head: How compassion encourages } \\
\text { Social Entrepreneurship }\end{array}$ & $\begin{array}{l}\text { Miller, Grimes, } \\
\text { McMullen e Vogus } \\
\text { (2012) }\end{array}$ & $\begin{array}{l}\text { Academy of } \\
\text { Management } \\
\text { Review }\end{array}$ & 184 \\
\hline 9 & $\begin{array}{l}\text { Personal values as a catalyst for } \\
\text { corporate social entrepreneurship }\end{array}$ & Hemingway (2005) & $\begin{array}{l}\text { Journal of } \\
\text { Business Ethics }\end{array}$ & 153 \\
\hline 10 & $\begin{array}{l}\text { The multiple faces of social } \\
\text { entrepreneurship: A review of } \\
\text { definitional issues based on } \\
\text { geographical and thematic criteria }\end{array}$ & $\begin{array}{l}\text { Bacq e Janssen } \\
\text { (2011) }\end{array}$ & $\begin{array}{l}\text { Entrepreneurship } \\
\text { And Regional } \\
\text { Development }\end{array}$ & 148 \\
\hline
\end{tabular}

Fonte: Elaborado pelos autores a partir da Web Of Science.

Mair e Marti (2006) entendem que o empreendedorismo social integra a criação de valor econômico e social. Para os autores, o empreendedorismo social pode ser entendido "como um processo que envolve o uso inovador e a combinação de recursos para buscar oportunidades de catalisar a mudança social e/ ou atender às necessidades sociais" (Mair \& Marti, 2006, p. 37). Discordando das intençóes puramente altruístas, os autores afirmam que o empreendedorismo social também pode gerar realização pessoal por meio da motivação do indivíduo. Os autores afirmam que o campo pode buscar suportes teóricos em quatro perspectivas, a saber: teoria da estruturação, empreendedorismo institucional, capital social e movimentos sociais.

Para Peredo e McLean (2006), o empreendedorismo social ocorre quando um indivíduo ou um grupo de pessoas tem como objetivo "criar valor social de algum tipo, e perseguir esse objetivo através de alguma combinação, reconhecer e explorar oportunidades para criar esse valor, empregar inovação, tolerar riscos e recusar aceitar limitações nos recursos disponíveis" (Peredo \& McLean, 2006, p. 56).

Dacin et al. (2010) colocam que os pesquisadores testam no empreendedorismo social os pressupostos e insights do empreendedorismo. Para os autores, o excesso de definições de empreendedorismo social dificulta o diálogo interdisciplinar e os avanços teóricos do campo. Assim, propõem definições conceituais do termo a partir de quatro fatores-chave: a personalidade dos empreendedores sociais, o setor de atuação, os recursos utilizados e o objetivo principal. Além da contribuição, os autores buscaram diferenciar o empreendedorismo social de outras formas de empreendedorismo, a saber: empreendedorismo convencional, institucional e cultural.

Short et al. (2009) realizaram uma revisão de literatura onde constatam que o campo do empreendedorismo social é marcado por artigos teóricos. Em relação aos empíricos, enfatizam a falta de hipóteses significativas, que podem gerar avanços teóricos para campo, e também a falta de rigidez 
metodológica. Os autores sugerem o uso de teorias estabelecidas como, por exemplo, teoria da contingência, teoria da descoberta, teoria da criação, teoria da difusão da inovação e teoria da dependência de recursos (Short et al., 2009).

Para Weerawardena e Mort (2006), as pesquisas em empreendedorismo social não consideram as características únicas dos empreendedores sociais e do contexto no qual eles atuam. Eles definem o empreendedorismo social "como um fenômeno comportamental operando dentro de restrições” (Weerawardena \& Mort, 2006, p. 33). A definição desses autores enfatiza restrições relacionadas a recursos e a importância do contexto para restringir ou estimular o empreendedorismo social.

Dacin et al. (2011) propõem uma agenda de pesquisa para o campo do empreendedorismo social que envolve um diálogo com temas relacionados às instituições, movimentos sociais, redes, cultura, cognição e identidade.

O empreendedorismo social, para Santos (2012), é importante dentro do modelo capitalista, pois resolve problemas negligenciados e falhas do mercado e, como resultado, produz externalidades positivas. Os empreendimentos sociais podem ser mais eficientes que o Estado no que se refere à resolução de problemas sociais - ressaltando que este discurso fortalece o discurso neoliberal, conforme Kibler et al. (2018).

O trabalho de Miller et al. (2012) analisa as motivações para o empreendedorismo social, bem como apresenta um modelo que envolve três mecanismos, os quais transformam compaixão em empreendedorismo social (Miller et al., 2012). Além disso, analisam as condições institucionais que favorecem essa transformação.

Hemingway (2005) trabalha o conceito de empreendedorismo social corporativo, que está relacionado com atividades socialmente responsáveis dentro de organizações. $\mathrm{O}$ foco do trabalho é entender como os valores pessoais influenciam a predisposição para o empreendedorismo social corporativo. A partir desses valores, dividiram os indivíduos em termos de predisposição para a atividade socialmente responsável e encontraram quatro categorias: ativos, frustrados, conformistas ou apáticos (Hemingway, 2005).

Bacq e Janssen (2011) destacam a falta de definição conceitual para o empreendedorismo social. Os autores compararam a definição americana e europeia de empreendedorismo social. A hipótese inicial era de que a diferença contextual, principalmente relacionada ao papel do governo e a diferente concepção de capitalismo, resultaria em conceitos diferentes. Entretanto, concluem que não existe uma divisão clara. Como agenda de pesquisa, propõem um diálogo com a nova teoria institucional e com a teoria da contingência.

\subsection{Intellectual base}

A análise da co-citação de autores está relacionada com os autores referenciados pelos artigos da busca. Uma co-citação ocorre quando um artigo cita dois autores ao mesmo tempo. Os autores mais co-citados podem ser considerados importantes, pois são citados por uma grande quantidade de trabalhos e, portanto, compõem o mainstream de pesquisas relacionadas ao empreendedorismo social. A Figura 4 mostra os autores mais cocitados. O tamanho do nó reflete o número de co-citações. 


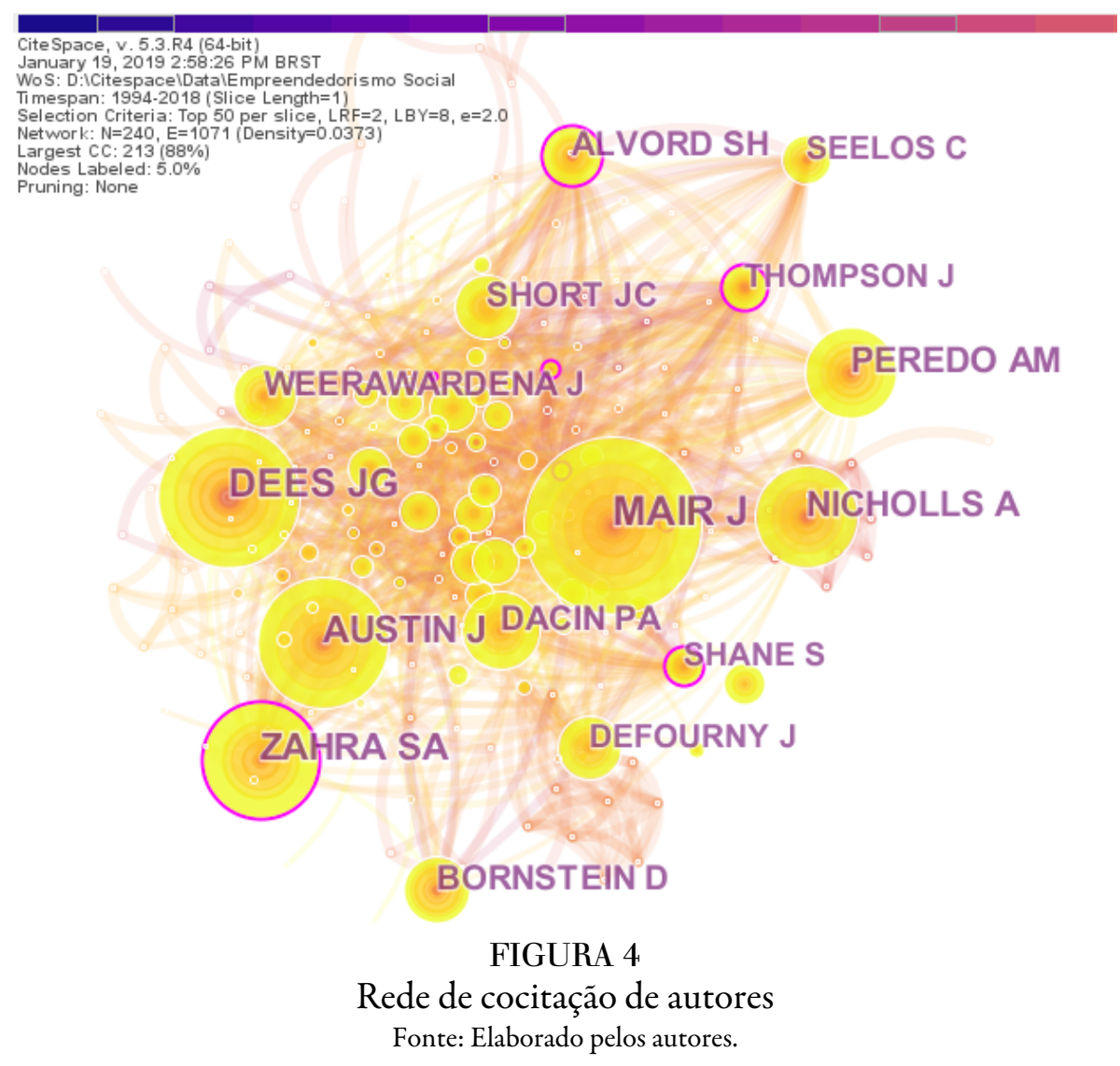

Alguns dos autores mais co-citados aparecem também com trabalhos entre os dez mais citados como, por exemplo, Johanna Mair (191 co-citações), Ana Maria Peredo (105), Peter Dacin (89), Jay Weerawardena (81) e Jeremy Short (75). Tal fato reforça a importância dos autores para o campo. Importante ressaltar que esses autores possuem outros trabalhos sobre empreendedorismo social. Apesar de não comporem o rol dos artigos mais citados, os demais autores são importantes. Alguns trabalham diretamente com empreendedorismo social como, por exemplo, J. Gregory Dees (150 co-citações). Uma busca no Google Scholar mostra que ele é autor de vários trabalhos sobre empreendedorismo social e seus trabalhos possuem grande número de citação. O mesmo acontece para James Austin (144 co-citações), Shaker A. Zahra (130), Alex Nicholls (114), David Bornstein (90), Sarah H. Alvord (75), Jacques Defourny (65), John L. Thompson (65), e Christian Seelos (62).

Importante ressaltar também a presença de Scott Shane (57) entre os autores mais co-citados. Apesar de não trabalhar diretamente com empreendedorismo social, o autor é importante para o campo do empreendedorismo. Scott Shane, em co-autoria com Sankaran Venkataraman, possui um dos trabalhos mais citados do empreendedorismo, a saber, "The Promise of Entrepreneurship as a Field of Research", que trata do conceito de oportunidades empreendedoras.

Adiante, a Figura 5 mostra a rede de co-citação de documentos, isto é, as referências utilizadas pelos artigos da busca. A co-citação de trabalhos, em sentido análogo à co-citação de autores, aponta os documentos que foram citados por dois ou mais trabalhos. Quanto maior o número de co-citações, mais importante é o documento para aquele campo. Novamente, o tamanho do nó está relacionado com a frequência de cocitação. Cada nó representa um documento e mostra o primeiro autor e o ano de publicação. 


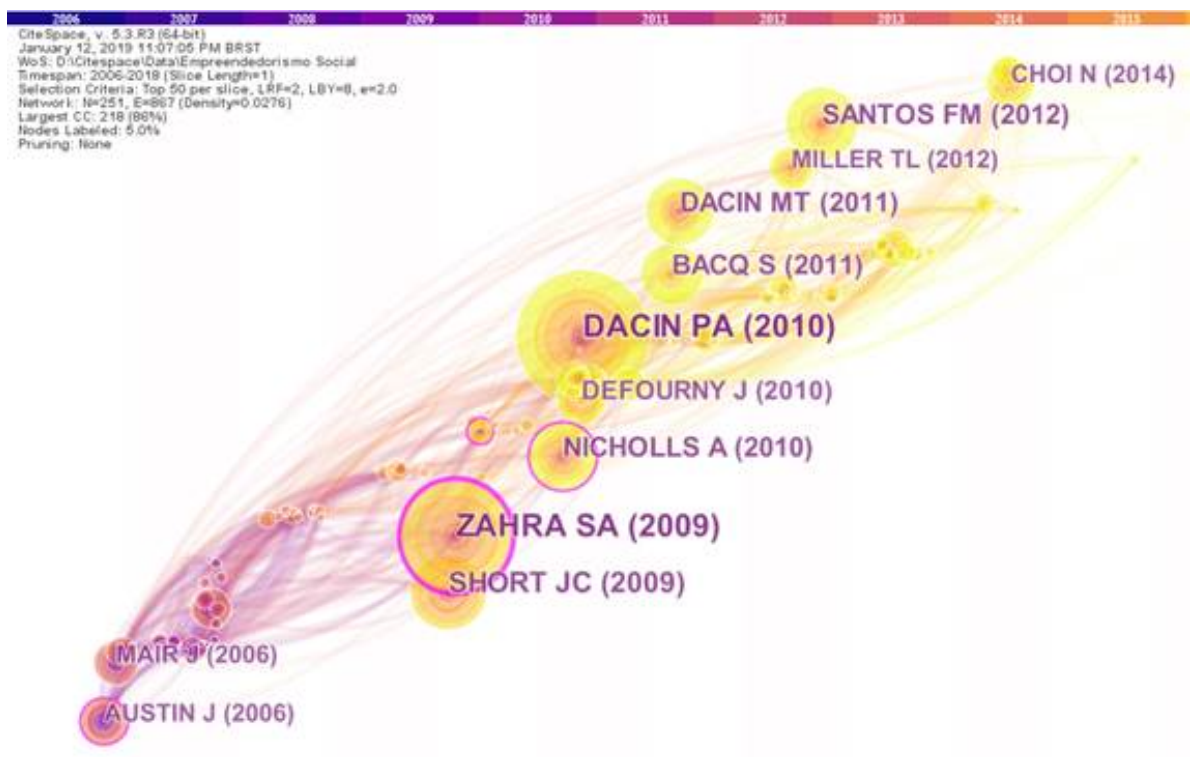

FIGURA 5

Artigos mais referenciados pela frente de pesquisa Fonte: Elaborada pelos autores a partir do CiteSpace.

Percebe-se que os trabalhos mais referenciados são recentes, diferente de outros campos do conhecimento, que possuem obras centrais publicadas ainda no século passado. Consequentemente, grande parte dos artigos mais referenciados constam também na Tabela 5 de artigos mais citados. No campo do empreendedorismo social, a frente de pesquisa, ou seja, os artigos mais citados da busca, coincide com a base intelectual.

Os demais trabalhos que aparecem na Figura 5 estão todos diretamente relacionados com empreendedorismo social. Nicholls (2010), por exemplo, apresenta os discursos, atores e narrativas que permeiam o campo do empreendedorismo social. O trabalho de Defourny e Nyssens (2010) busca convergências e divergências conceituais do empreendedorismo em contextos distintos. Choi e Majumdar (2014) discutem o empreendedorismo social enquanto um conceito contestado e multifacetado. Por sua vez, Zahra et al. (2009) constroem uma tipologia para o empreendedorismo social. Por fim, Austin et al. (2012) realizaram uma comparação entre empreendedorismo comercial e empreendedorismo social.

Observa-se, portanto, que os documentos mais co-citados pelos artigos da busca estão todos diretamente relacionados com o empreendedorismo social. Uma hipótese para isso é a consolidação enquanto campo de pesquisa autônomo, pois já conta com referências próprias. Por outro lado, isso pode significar falta de um maior diálogo com outras áreas do conhecimento, o que poderia ajudar no desenvolvimento teórico e metodológico do campo.

\section{UMA AGENDA DE PESQUISA PARA O EMPREENDEDORISMO SOCIAL}

Para construir a agenda de pesquisas futuras (Quadro 1), foram analisadas as sugestões de pesquisas apresentadas nos artigos publicados em 2018. A agenda de pesquisa é recente e apresenta lacunas que podem motivar trabalhos futuros. Ressalta-se que não são todos os artigos que apresentam sugestões de pesquisa futura. Além disso, alguns artigos sugerem agendas que estão mais relacionadas com outros campos, tendo o empreendedorismo social apenas como pano de fundo. A agenda de pesquisa foi construída a partir de temas que apareceram com mais frequência, o que resultou em quatro tópicos de sugestões futuras. 


\begin{tabular}{|c|c|}
\hline 1) Contexto institucional & 2) Bricolagem e empreendedorismo social \\
\hline $\begin{array}{l}\text { Influência do ambiente institucional formal } \\
\text { (organizações, leis, regulamentos) e informal (cultura, } \\
\text { valores) no empreendedorismo social. } \\
\text { Muralidharan e Pathak (2018); Kolaković, Turuk e } \\
\text { Turčić (2018); Hermelin e Rusten (2018); Popov, } \\
\text { Veretennikova, Naumov e Kozinskaya (2018); } \\
\text { Sooampon (2018). }\end{array}$ & \multirow[t]{3}{*}{$\begin{array}{l}\text { Pesquisas teóricas e empíricas envolvendo o uso do } \\
\text { conceito de bricolagem no campo do } \\
\text { empreendedorismo social. } \\
\text { Janssen, Fayolle e Wuilaume (2018); Bojica, } \\
\text { Jiménez, Nava e Fuentes-Fuentes (2018); Servantie e } \\
\text { Rispal (2018); Zollo et al. (2018) }\end{array}$} \\
\hline $\begin{array}{l}\text { Como ocorre a tomada de decisão em um contexto } \\
\text { marcado por múltiplas lógicas institucional. } \\
\text { Rossignoli, Ricciardi e Bonomi (2018); Kimmitt e } \\
\text { Muñoz (2018) }\end{array}$ & \\
\hline $\begin{array}{l}\text { Aproximação teórica entre empreendedorismo social e } \\
\text { teoria institucional. } \\
\text { Starnawska (2018); Kokko (2018) }\end{array}$ & \\
\hline 3) Impacto do empreendedorismo social & $\begin{array}{l}\text { 4) Aprofundar o conceito de empreendedorismo } \\
\text { social }\end{array}$ \\
\hline $\begin{array}{l}\text { Medidas e metodologias para avaliar } \circ \text { impacto de } \\
\text { empreendimentos sociais. }\end{array}$ & $\begin{array}{l}\text { Revisões de literatura para mapear e sistematizar a } \\
\text { literatura sobre empreendedorismo social. }\end{array}$ \\
\hline $\begin{array}{l}\text { Lumpkin et al. (2018); Kibler et al. (2018); Holland et al. } \\
\text { (2018) }\end{array}$ & Collavo (2018); Macke et al. (2018) \\
\hline $\begin{array}{l}\text { Quais são os resultados do empreendimento social? } \\
\text { Quais os tipos de capital que ele gera? Qual o alcance } \\
\text { espacial desses resultados? } \\
\text { Lumpkin et al. (2018); Jiménez-Conorado, Hernández- } \\
\begin{array}{l}\text { Palmae Pitre-Redondo (2018); Freudenberg e } \\
\text { Halberstadt (2018) }\end{array}\end{array}$ & $\begin{array}{l}\text { Aprofundamento teórico do conceito de } \\
\text { empreendedorismo social. } \\
\text { Aquino et al. (2018); Aliaga-Islae Huybrechts (2018); } \\
\text { Lumpkin et al. (2018) }\end{array}$ \\
\hline
\end{tabular}

Quadro 1 -Agenda e sugestões para pesquisas futuras

Fonte: Elaborado pelos autores a partir da Web Of Science.

O primeiro está relacionado com o contexto institucional e destaca a necessidade de uma melhor compreensão sobre os efeitos das instituições formais e informais no empreendedorismo social. Em outras palavras, tem como objetivo entender como as organizações, leis, regulamentos, valores, culturas e normas sociais implícitas e explícitas estimulam ou restringem o empreendedorismo social, além de entender como as múltiplas lógicas institucionais, inerentes ao empreendedorismo social, influenciam o processo de tomada de decisão. Portanto, o primeiro tópico demanda uma aproximação entre o empreendedorismo social e as teorias institucionais.

Por sua vez, o segundo tópico destaca a necessidade de aproximação entre empreendedorismo social e o conceito de bricolagem. A bricolagem está relacionada com o uso criativo dos recursos disponíveis, ou seja, uma combinação criativa dos recursos para alcançar um determinado fim. Como os empreendedores sociais possuem recursos limitados e maior dificuldade para atrair financiamento para suas atividades, a ideia de bricolagem pode ser útil para o campo.

O terceiro tópico aponta a necessidade - e dificuldade - de criar medidas e metodologias para mensurar os resultados de empreendimentos sociais. Por ter objetivos sociais, é preciso discutir os resultados do empreendedorismo social em termos da criação não apenas de capital econômico, mas de outros capitais como o social e o cultural, por exemplo. Além disso, existe uma indefinição sobre o alcance geográfico dos benefícios gerados pelo empreendimento social e lacunas teóricas e metodológicas relacionadas à medição de seu impacto.

Por fim, por ser um campo recente e um conceito ainda indefinido, o quarto tópico destaca a necessidade de aprofundamentos e discussões teóricas sobre o conceito de empreendedorismo social. Nesse sentido, revisões (sistemáticas ou não) são necessárias para elencar os conceitos já apresentados, as categorias centrais do campo e, a partir disso, realizar o aprofundamento dessas categorias e conceitos. 


\section{Considerações Finais}

Diante de problemas sociais de diversas ordens (econômicos, ambientais, sociais) e de uma redução do aparelho de Estado a partir do advento do discurso neoliberal, o empreendedorismo social pode ser visto como um instrumento importante para a redução do impacto desses problemas e, consequentemente, de mudança social (Warnecke, 2018; Kibler et al., 2018). Assim, o debate sobre o empreendedorismo social torna-se importante dentro do campo do empreendedorismo. Nesse sentido, surgem eventos e periódicos específicos sobre o tema, além de novos pesquisadores e discussões teóricas e metodológicas, o que faz com que o campo do empreendedorismo social seja consolidado.

Entretanto, não existe ainda uma definição única de empreendedorismo social e o campo encontra-se em construção. Nesse sentido, este trabalho teve como objetivos analisar como se configura a literatura internacional sobre empreendedorismo social e construir uma agenda de pesquisa para estudos futuros. Para alcançar os objetivos propostos utilizamos uma análise bibliométrica. Esse tipo de revisão de literatura tem um caráter mais quantitativo, mapeando o número de publicações ao longo dos anos, autores e trabalhos mais citados, palavras-chaves mais utilizadas, entre outros aspectos, mas possibilita também elencar aspectos qualitativos e fazer inferências sobre o campo.

Os resultados apresentados fornecem uma compreensão panorâmica das pesquisas sobre empreendedorismo social, o que permite a identificação de condutores, ou seja, de trabalhos, autores e periódicos centrais para o campo. Além disso, ao mostrar as palavras-chave com maior número de coocorrências e a explosão de palavras-chave ao longo dos anos, o estudo permite identificar temas centrais e recentes nas pesquisas sobre empreendedorismo social. Ainda, ao apresentar uma agenda de pesquisa baseada em estudos recentes, o estudo apresenta lacunas e novos tópicos para pesquisa. Dessa forma, a contribuição deste estudo, a partir do grande volume de publicações e informações disponível sobre empreendedorismo social, consiste em elucidar o estado da arte desse campo ainda em construção.

Em síntese, observamos que o campo ainda é recente, o que fica claro quando se observa como são recentes as referências mais citadas (a base intelectual). Além disso, a explosão do número de publicações acontece apenas a partir de 2006. Observamos, ainda, que as palavras-chave mais citadas (enterprise, innovation, organization, opportunity, business, performance, management) estão relacionadas com empreendedorismo privado, o que mostra uma forte ligação com o campo raiz. Entretanto, ao analisar as referências mais citadas, observa-se uma tendência de separação entre empreendedorismo social e privado, com o primeiro consolidando uma literatura própria. Em relação aos países, foi possível destacar a grande predominância dos Estados Unidos como produtor de trabalhos sobre empreendedorismo social. Entretanto, não identificamos nenhuma instituição específica que possa ser considerada referência.

Por fim, sugerimos como agenda de pesquisa revisões de literatura de caráter qualitativo. Sugerimos ainda que sejam feitas revisões mais voltadas para o âmbito nacional, no intuito de verificar o que a academia brasileira vem escrevendo sobre empreendedorismo social. Além disso, é importante observar a agenda de pesquisa dos artigos mais recentes - e também a elaborada neste trabalho - para identificar para onde o campo do empreendedorismo social deve caminhar nos próximos anos.

\section{REFERÊNCIAS}

Aliaga-Isla, R., \& Huybrechts, B. (2018). From "Push Out" to "Pull In" together: An analysis of social entrepreneurship definitions in the academic field. Journal of cleaner production, 205, 645-660.

Alvarez, S. A., \& Barney, J. B. (2007). Discovery and creation: Alternative theories of entrepreneurial action. Strategic entrepreneurship journal, $1(1-2), 11-26$.

Aquino, R. S., Lück, M., \& Schänzel, H. A. (2018). A conceptual framework of tourism social entrepreneurship for sustainable community development. Journal of Hospitality and Tourism Management, 37, 23-32. 
Austin, J., Stevenson, H., \& Wei-Skillern, J. (2012). Social and commercial entrepreneurship: same, different, or both? Revista de Administração, 47(3), 370-384.

Bacq, S., \& Janssen, F. (2011). The multiple faces of social entrepreneurship: A review of definitional issues based on geographical and thematic criteria. Entrepreneurship \& Regional Development, 23(5-6), 373-403.

Bojica, A. M., Ruiz Jiménez, J. M., Ruiz Nava, J. A., \& Fuentes-Fuentes, M. M. (2018). Bricolage and growth in social entrepreneurship organisations. Entrepreneurship \& Regional Development, 30(3-4), 362-389.

Chandra, Y. (2017). Social entrepreneurship as emancipatory work. Journal of Business Venturing, 32(6), 657-673.

Chen, C. (2006). CiteSpace II: Detecting and visualizing emerging trends and transient patterns in scientific literature. Journal of the American Society for information Science and Technology, 57(3), 359-377.

Choi, N., \& Majumdar, S. (2014). Social entrepreneurship as an essentially contested concept: Opening a new avenue for systematic future research. Journal of business venturing, 29(3), 363-376.

Collavo, T. (2018). Unpacking social entrepreneurship: exploring the definition chaos and its consequences in England. Journal Of Entrepreneurship, Management And Innovation, 14(2), 19-47.

Dacin, M. T., Dacin, P. A., \& Tracey, P. (2011). Social entrepreneurship: A critique and future directions. Organization science, 22(5), 1203-1213.

Dacin, P. A., Dacin, M. T., \& Matear, M. (2010). Social entrepreneurship: Why we don't need a new theory and how we move forward from here. Academy of management perspectives, 24(3), 37-57.

Dees, Gregory J. (1998), 'The meaning of "Social Entrepreneurship"', Kauffman Center for Entrepreneurial Leadership, Stanford University, Stanford, CA.

Defourny, J., \& Nyssens, M. (2010). Conceptions of social enterprise and social entrepreneurship in Europe and the United States: Convergences and divergences. Journal of social entrepreneurship, 1(1), 32-53.

Fischer, R. M., \& Comini, G. (2012). Sustainable development: from responsibility to entrepreneurship. Revista de Administração (São Paulo), 47(3), 363-369. https://doi.org/10.1590/S0080-21072012000300002

Freudenberg, J., \& Halberstadt, J. (2018). How to Integrate Refugees Into the Workforce-Different Opportunities for (Social) Entrepreneurship. Problemy Zarządzania, (1/2018 (73), t. 2), 40-60.

Hemingway, C. A. (2005). Personal values as a catalyst for corporate social entrepreneurship. Journal of business ethics, 60(3), 233-249.

Hermelin, B., \& Rusten, G. (2018). A place-based approach to social entrepreneurship for social integration-Cases from Norway and Sweden. Local Economy, 33(4), 367-383. https://doi.org/10.1177/0269094218777900

Holland, J. H., Hatcher, W., \& Poole, V. B. (2018). Social entrepreneurship in Trujillo, Peru: The case of Nisolo. Community Development, 49(3), 312-323. https://doi.org/10.1080/15575330.2018.1462837

Janssen, F., Fayolle, A., \& Wuilaume, A. (2018). Researching bricolage in social entrepreneurship. Entrepreneurship \& Regional Development, 30(3-4), 450-470.

Jiménez-Conorado, A., Hernández-Palma, H., \& Pitre-Redondo, R. (2018). Emprendimiento social y su repercusión en el desarrollo económico desde los negocios inclusivos (Colombia). Rev. Logos, ciencia y tecnología, 10.

Kibler, E., Salmivaara, V., Stenholm, P., \& Terjesen, S. (2018). The evaluative legitimacy of social entrepreneurship in capitalist welfare systems. Journal of World Business, 53(6), 944-957.

Kimmitt, J., \& Muñoz, P. (2018). Sensemaking the 'social' in social entrepreneurship. International Small Business Journal, 36(8), 859-886.

Kokko, S. (2018). Social entrepreneurship: creating social value when bridging holes. Social Enterprise Journal, 14(4), 410-428.

Kolaković, M., Turuk, M., \& Turčić, I. (2018). Social Entrepreneurship: Strategic Development in Croatia. Zagreb International Review of Economics \& Business, 21(2), 129-143.

Kummitha, R. K. R. (2018). Institutionalising design thinking in social entrepreneurship: A contextual analysis into social and organizational processes. Social Enterprise Journal, 14(1), 92-107.

Liu, W., Gu, M., Hu, G., Li, C., Liao, H., Tang, L., \& Shapira, P. (2014). Profile of developments in biomass-based bioenergy research: a 20-yearperspective. Scientometrics, 99(2), 507-521. 
Lumpkin, G. T., Bacq, S., \& Pidduck, R. J. (2018). Where Change Happens: Community - Level Phenomena in Social Entrepreneurship Research. Journal of Small Business Management, 56(1), 24-50.

Macke, J., Sarate, J. R., Domeneghini, J., \& Silva, K. (2018). Where do we go from now? Research framework for social entrepreneurship. Journal of Cleaner Production, 183, 677-685.

Mair, J., \& Marti, I. (2006). Social entrepreneurship research: A source of explanation, prediction, and delight. Journal of world business, 41(1), 36-44.

Mair, J., \& Noboa, E. (2006). Social entrepreneurship: How intentions to create a social venture are formed. Social entrepreneurship, 121-135. https://doi.org/10.1057/9780230625655_8

Miller, T. L., Grimes, M. G., McMullen, J. S., \& Vogus, T. J. (2012). Venturing for others with heart and head: How compassion encourages social entrepreneurship. Academy of management review, 37(4), 616-640.

Muralidharan, E., \& Pathak, S. (2018). Sustainability, transformational leadership, and social entrepreneurship. Sustainability, 10(2), 567.

Nicholls, A. (2010). The legitimacy of social entrepreneurship: reflexive isomorphism in a pre - paradigmatic field. Entrepreneurship theory and practice, 34(4), 611-633.

Nicolopoulou, K. (2014). Social entrepreneurship between cross - currents: toward a framework for theoretical restructuring of the field. Journal of Small Business Management, 52(4), 678-702.

Oliveira, E. M. (2004). Empreendedorismo social no Brasil: atual configuração, perspectivas e desafios-notas introdutórias. Revista da FAE, 7(2). Recuperado de https://revistafae.fae.edu/revistafae/article/view/416

Parente, C., Costa, D., Santos, M., \& Chaves, R. R. (2011). Empreendedorismo social: contributos teóricos para a sua definição. XIV Encontro Nacional de Sociologia Industrial, das Organizações e do Trabalho Emprego e coesão social: da crise de regulação à hegemonia da globalização, Lisboa, Portugal. Recuperado de <https://www.researchgate.net/ publication/277158961_Empreendedorismo_social_contributos_teoricos_para_a_sua_definicao >;.

Peredo, A. M., \& McLean, M. (2006). Social entrepreneurship: A critical review of the concept. Journal of world business, 41(1), 56-65.

Popov, E., Veretennikova, A. Y., Naumov, I. Y., \& Kozinskaya, K. M. (2018). Non-Formal Institutional Environment of Social Entrepreneurship. Economic And Social Changes-Facts Trends Forecast, 11(4), 217-234.

Prado, J. W., Castro Alcântara, V., Melo Carvalho, F., Vieira, K. C., Machado, L. K., \& Tonelli, D. F. (2016). Multivariate analysis of credit risk and bankruptcy research data: a bibliometric study involving different knowledge fields (1968-2014). Scientometrics, 106(3), 1007-1029.

Rivera, R. G., Santos, D., Martín-Fernández, M., Requero, B., \& Cancela, A. (2018). Predicting attitudes and behavioural intentions towards social entrepreneurship: the role of servant leadership in young people/ Predicción de las actitudes y las intenciones conductuales hacia el emprendimiento social: el papel del liderazgo de servicio en los jóvenes. Revista de Psicología Social, 33(3), 650-681.

Rossignoli, C., Ricciardi, F., \& Bonomi, S. (2018). Organizing for Commons-Enabling Decision-Making Under Conflicting Institutional Logics in Social Entrepreneurship. Group Decision and Negotiation, 27(3), 417-443.

Saebi, T., Foss, N. J., \& Linder, S. (2019). Social entrepreneurship research: Past achievements and future promises. Journal of Management, 45(1), 70-95.

Santos, F. M. (2012). A positive theory of social entrepreneurship. Journal of business ethics, 111(3), 335-351.

Schneider, A. (2017). Social Entrepreneurship, Entrepreneurship, Collectivism, and Everything in Between: Prototypes and Continuous Dimensions. Public Administration Review, 77(3), 421-431.

Shane, S., \& Venkataraman, S. (2000). The promise of entrepreneurship as a field of research. Academy of management review, 25(1), 217-226. Recuperado de https://www.sjsu.edu/people/john.estill/courses/158s15/The\%20Promise\%20of\%20Entrepreneurship\%20as\%20a\%20Field\%20of\%20Study.pdf;.

Short, J. C., Moss, T. W., \& Lumpkin, G. T. (2009). Research in social entrepreneurship: Past contributions and future opportunities. Strategic entrepreneurship journal, 3(2), 161-194. 
Smachylo, V., Khalina, V., \& Kylnytska, Y. (2018). Development of the social entrepreneurship in Ukraine as an innovative form of the business. Marketing and Management of Innovations, 1, 235-246.

Sooampon, S. (2018). The birth of social entrepreneurship within a Thai university. Journal of Asia Business Studies, $12(2), 162-172$.

Starnawska, M. (2018). Pronouncement of embedded agency in the field of social entrepreneurship. Problemy Zarzadzania, (1/2018 (73), t. 2), 229-239.

Stephan, U., Uhlaner, L. M., \& Stride, C. (2015). Institutions and social entrepreneurship: The role of institutional voids, institutional support, and institutional configurations. Journal of International Business Studies, 46(3), 308-331.

Warnecke, T. (2018). Social Entrepreneurship in China: Driving Institutional Change. Journal of Economic Issues, 52(2), 368-377.

Weerawardena, J., \& Mort, G. S. (2006). Investigating social entrepreneurship: A multidimensional model. Journal of world business, 41(1), 21-35.

Young, D. R., \& Lecy, J. D. (2014). Defining the universe of social enterprise: Competing metaphors. Voluntas: international journal of voluntary and nonprofit organizations, 25(5), 1307-1332.

Zahra, S. A., Gedajlovic, E., Neubaum, D. O., \& Shulman, J. M. (2009). A typology of social entrepreneurs: Motives, search processes and ethical challenges. Journal of business venturing, 24(5), 519-532.

Zollo, L., Rialti, R., Ciappei, C., \& Boccardi, A. (2018). Bricolage and Social Entrepreneurship to Address Emergent Social Needs: A 'Deconstructionist' Perspective. Journal of Entrepreneurship, Management And Innovation, 14(2), 3-18. https://doi.org/10.7341/20181422 